\title{
Satellite cell content is specifically reduced in type II skeletal muscle fibers in the elderly
}

Citation for published version (APA):

Verdijk, L. B., Koopman, R., Schaart, G., Meijer, K., Savelberg, H. H. C. M., \& van Loon, L. J. (2007). Satellite cell content is specifically reduced in type II skeletal muscle fibers in the elderly. American Journal of Physiology : Endocrinology and Metabolism, 292, E151-E157.

https://doi.org/10.1152/ajpendo.00278.2006

Document status and date:

Published: 01/01/2007

DOI:

10.1152/ajpendo.00278.2006

Document Version:

Publisher's PDF, also known as Version of record

Document license:

Taverne

Please check the document version of this publication:

- A submitted manuscript is the version of the article upon submission and before peer-review. There can be important differences between the submitted version and the official published version of record.

People interested in the research are advised to contact the author for the final version of the publication, or visit the DOI to the publisher's website.

- The final author version and the galley proof are versions of the publication after peer review.

- The final published version features the final layout of the paper including the volume, issue and page numbers.

Link to publication

\footnotetext{
General rights rights.

- You may freely distribute the URL identifying the publication in the public portal. please follow below link for the End User Agreement:

www.umlib.nl/taverne-license

Take down policy

If you believe that this document breaches copyright please contact us at:

repository@maastrichtuniversity.nl

providing details and we will investigate your claim.
}

Copyright and moral rights for the publications made accessible in the public portal are retained by the authors and/or other copyright owners and it is a condition of accessing publications that users recognise and abide by the legal requirements associated with these

- Users may download and print one copy of any publication from the public portal for the purpose of private study or research.

- You may not further distribute the material or use it for any profit-making activity or commercial gain

If the publication is distributed under the terms of Article $25 \mathrm{fa}$ of the Dutch Copyright Act, indicated by the "Taverne" license above, 


\title{
Satellite cell content is specifically reduced in type II skeletal muscle fibers in the elderly
}

\author{
Lex B. Verdijkk, ${ }^{1}$ René Koopman, ${ }^{1,2}$ Gert Schaart, ${ }^{1}$ Kenneth Meijer, ${ }^{1}$ \\ Hans H. C. M. Savelberg, ${ }^{1}$ and Luc J. C. van Loon ${ }^{1,2}$ \\ Departments of ${ }^{1}$ Movement Sciences and ${ }^{2}$ Human Biology, Nutrition and Toxicology Research \\ Institute Maastricht (NUTRIM), Maastricht University, Maastricht, The Netherlands
}

Submitted 13 June 2006; accepted in final form 17 August 2006

\begin{abstract}
Verdijk LB, Koopman R, Schaart G, Meijer K, Savelberg HH, van Loon LJ. Satellite cell content is specifically reduced in type II skeletal muscle fibers in the elderly. Am J Physiol Endocrinol Metab 292: E151-E157, 2007. First published August 22, 2006; doi:10.1152/ajpendo.00278.2006.-Satellite cells (SC) are essential for skeletal muscle growth and repair. Because sarcopenia is associated with type II muscle fiber atrophy, we hypothesized that SC content is specifically reduced in the type II fibers in the elderly. A total of eight elderly (E; $76 \pm 1 \mathrm{yr}$ ) and eight young (Y; $20 \pm 1 \mathrm{yr})$ healthy males were selected. Muscle biopsies were collected from the vastus lateralis in both legs. ATPase staining and a pax7-antibody were used to determine fiber type-specific SC content (i.e., pax7positive SC) on serial muscle cross sections. In contrast to the type I fibers, the proportion and mean cross-sectional area of the type II fibers were substantially reduced in E vs. Y. The number of SC per type I fiber was similar in E and Y. However, the number of SC per type II fiber was substantially lower in E vs. Y $(0.044 \pm 0.003$ vs. $0.080 \pm 0.007 ; P<0.01)$. In addition, in the type II fibers, the number of SC relative to the total number of nuclei and the number of SC per fiber area were also significantly lower in E. This study is the first to show type II fiber atrophy in the elderly to be associated with a fiber type-specific decline in SC content. The latter is evident when SC content is expressed per fiber or per fiber area. The decline in SC content might be an important factor in the etiology of type II muscle fiber atrophy, which accompanies the loss of skeletal muscle with aging.
\end{abstract}

sarcopenia; muscle stem cells; atrophy; metabolism

THE GRADUAL LOSS OF skeletal muscle mass with aging, or sarcopenia, represents a major factor determining the decline in functional capacity, mobility, and general health in the elderly. Muscle mass represents a main determinant of muscle strength and has been strongly associated with performance in activities of daily living and the level of independence in the elderly (16, 36,49 ). Much work has been devoted to describing the alterations in skeletal muscle that occur with aging. The most consistent findings have been the decline in the total number of muscle fibers and the specific atrophy of the type II fibers, both contributing to the loss of skeletal muscle mass $(18,28,30)$. In accordance, type II muscle fiber atrophy and necrosis have been shown to result in a reduced (area) proportion of type II muscle fibers in skeletal muscle tissue in the elderly $(15$, 28, 29).

Although the exact mechanisms that cause sarcopenia remain to be elucidated, the hypothesis that satellite cells could

\footnotetext{
Address for reprint requests and other correspondence: L. Verdijk, Dept. of Movement Sciences, Faculty of Health Sciences, Maastricht University, PO Box 616, 6200 MD Maastricht, The Netherlands (e-mail: Lex. Verdijk@bw.unimaas.nl).
}

play an important role in this age-related loss of skeletal muscle mass has recently gained much interest. Satellite cells (SC), or "muscle stem cells," are the sole source for the generation of new myonuclei in vivo in skeletal muscle tissue $(2,34,35)$. As such, SC seem to be essential for the repair and hypertrophy of skeletal muscle tissue. Normally, SC lie quiescent between the basal lamina and the plasma membrane of muscle fibers (32). On activation and subsequent proliferation, the majority of these SC differentiate to form new myonuclei that either fuse with existing fibers or generate new fibers, while a small proportion returns to quiescence $(24,50)$.

Because SC are responsible for the maintenance of skeletal muscle mass, a decrease in the number of SC or in their ability to become activated and proliferate in response to anabolic stimuli is likely to result in impaired skeletal muscle structure and function (44). Although the latter has been speculated to occur in sarcopenia, studies investigating the effects of aging on skeletal muscle SC content in humans have been inconclusive. Whereas some studies reported both a reduced number of SC per muscle fiber and a smaller proportion of SC relative to the number of myonuclei in the elderly $(22,38)$, other studies have failed to observe such differences $(15,20,40)$. Although it has been reported that no differences exist in the number of SC between type I and II muscle fibers in young adults (23), it could be speculated that the specific type II muscle fiber atrophy with aging is associated with a fiber type-specific reduction in SC content. Such a fiber type-specific reduction in SC content could represent an important factor in the etiology of sarcopenia and might explain the apparent discrepancy in the literature regarding the effects of aging on muscle fiber SC content.

In the present study, we assessed skeletal muscle fiber type-specific characteristics and fiber type-specific satellite cell content in young and elderly men. Therefore, skeletal muscle biopsy samples were taken from the vastus lateralis in both the left and right legs of eight young ( $20 \pm 1 \mathrm{yr})$ and eight elderly (76 $\pm 1 \mathrm{yr}$ ) lean males. Immunohistological staining of muscle cross sections was performed to assess muscle fiber typespecific SC content and muscle fiber characteristics.

\section{METHODS}

Subjects. Eight elderly ( $76 \pm 1 \mathrm{yr})$ and eight young $(20 \pm 1 \mathrm{yr})$, body weight-matched, male volunteers with no history of participating in any regular exercise program were recruited to participate in the present study. Characteristics of subjects are shown in Table 1. All

\footnotetext{
The costs of publication of this article were defrayed in part by the payment of page charges. The article must therefore be hereby marked "advertisement" in accordance with 18 U.S.C. Section 1734 solely to indicate this fact.
} 
Table 1. Subject characteristics

\begin{tabular}{lcc}
\hline \hline & Young $(n=8)$ & Elderly $(n=8)$ \\
\hline Age, yr & $20 \pm 1$ & $76 \pm 1^{*}$ \\
Weight, kg & $73.7 \pm 3.2$ & $75.5 \pm 2.1$ \\
Height, m & $1.81 \pm 0.03$ & $1.71 \pm 0.01^{*}$ \\
BMI, kg/m ${ }^{2}$ & $22.5 \pm 1.1$ & $25.7 \pm 0.7^{*}$ \\
Leg volume, liters & $9.4 \pm 0.4$ & $8.2 \pm 0.3^{*}$ \\
Hb A 1 c $\%$ & $5.0 \pm 0.2$ & $5.7 \pm 0.1^{*}$ \\
Basal glucose, mmol/1 & $5.3 \pm 0.1$ & $5.4 \pm 0.2$ \\
Basal insulin, mU/l & $12.8 \pm 1.1$ & $10.2 \pm 1.5$ \\
HOMA-IR & $3.0 \pm 0.3$ & $2.5 \pm 0.4$ \\
1-RM leg extension, kg & $108 \pm 4$ & $78 \pm 4^{*}$ \\
1-RM leg press, kg & $204 \pm 7$ & $151 \pm 7^{*}$ \\
\hline
\end{tabular}

Values are means \pm SE. BMI, body mass index; HOMA-IR, homeostasis model assessment of insulin resistance (31); 1-RM, 1-repetition maximum. *Significantly different compared with the young $(P<0.05)$.

subjects were informed on the nature and possible risks of the experimental procedures before their written informed consent was obtained. This study was approved by the Medical Ethics Committee of the Academic Hospital, Maastricht.

Pretesting. The medical histories of subjects were evaluated, and an oral glucose tolerance test was performed at least $2 \mathrm{wk}$ before the start of the trials $(1,31)$. Subjects with orthopedic and/or cardiovascular abnormalities or type 2 diabetes were excluded from participation. After selection for this study, maximal strength was assessed in two one-repetition maximum (1-RM) strength tests on a leg press and leg extension machine, respectively. First, a familiarization trial was performed. Proper lifting technique was demonstrated and practiced for each of the two lower limb exercises. Thereafter, maximum strength was estimated using the multiple repetitions testing procedure (33). In an additional session, at least 10 days before muscle biopsy collection, each subject's 1-RM was determined. After warming up, the load was set at $90-95 \%$ of the estimated maximum strength and increased after each successful lift until failure. A 3-min resting period between subsequent attempts was allowed. A repetition was valid if the subject was able to complete the entire lift in a controlled manner without assistance.

The weight and height of subjects were measured, and leg volume was determined as described previously (21). In short, leg circumference and height were measured at seven different sites, dividing the leg into six segments. The volume of each segment was calculated by treating each segment as a truncated cone, using the anthropometric measurements for determining the height and the surface areas of each cone. All subjects were instructed to refrain from strenuous physical activity for 3 days before muscle biopsy collection and to maintain their normal habitual dietary intake. On the day before biopsy collection, a standardized meal was provided, and from 9:00 PM, subjects remained fasted.

Muscle biopsies. After an overnight fast, subjects arrived at the laboratory by car or public transportation at 8:00 AM. After $30 \mathrm{~min}$ of supine rest, a basal venous blood sample was collected. After local anesthesia, percutaneous needle biopsies $(50-80 \mathrm{mg})$ were taken from the vastus lateralis muscle $\sim 15 \mathrm{~cm}$ above the patella in both the left and right legs of each subject (3). Any visible nonmuscle tissue was removed from the biopsy samples, which were then frozen in liquid nitrogen-cooled isopentane, embedded in Tissue-Tek (Sakura Finetek, Zoeterwoude, The Netherlands), and stored at $-80^{\circ} \mathrm{C}$ until further analyses.

Immunohistochemistry. From all biopsies, 5- $\mu$ m-thick cryosections were cut at $-20^{\circ} \mathrm{C}$ and samples from the left and right leg of each subject were mounted together on uncoated glass slides. Care was taken to properly align the samples for cross-sectional fiber analyses. Slides from elderly and young subjects were stained simultaneously to ensure identical staining efficiency.
An ATPase staining was performed after acid preincubation to determine muscle fiber type as described previously $(5,8,9)$. Instead of dehydration of the slides at the end of the ATPase staining procedure (5), sections were stained with anti-laminin (polyclonal rabbit anti-laminin; Sigma, Zwijndrecht, The Netherlands) and thereafter with the appropriate secondary antibody goat anti-rabbit IgG AlexaFluor488 (Molecular Probes, Invitrogen, Breda, The Netherlands). Nuclei were stained with 4',6-diamidino-2-phenylindole (DAPI; Molecular Probes), similar to the procedures described below. At a $\mathrm{pH}$ of 4.45 , we were able to differentiate between black (type I), white (type IIa), and intermediate (type IIb/IIx) fibers (Fig. 1). The assessment of muscle fiber typing at this $\mathrm{pH}$ was validated by staining serial muscle cross sections of three young and three elderly subjects with myosin heavy chain (MHC)-I and MHC-IIa antibodies [A4.840 and N2.261, respectively; Developmental Studies Hybridoma Bank (DSHB), Iowa City, IA]. Because too few type IIb/IIx fibers were present for reliable SC counts in some of the biopsies, SC content and fiber characteristics were assessed in type I and type II muscle fibers only.

Immunostaining for the detection of myocellular SC content was performed on serial cross sections with both pax7 (mouse anti-pax7, DSHB), which marks both quiescent and activated SC $(43,50)$, and
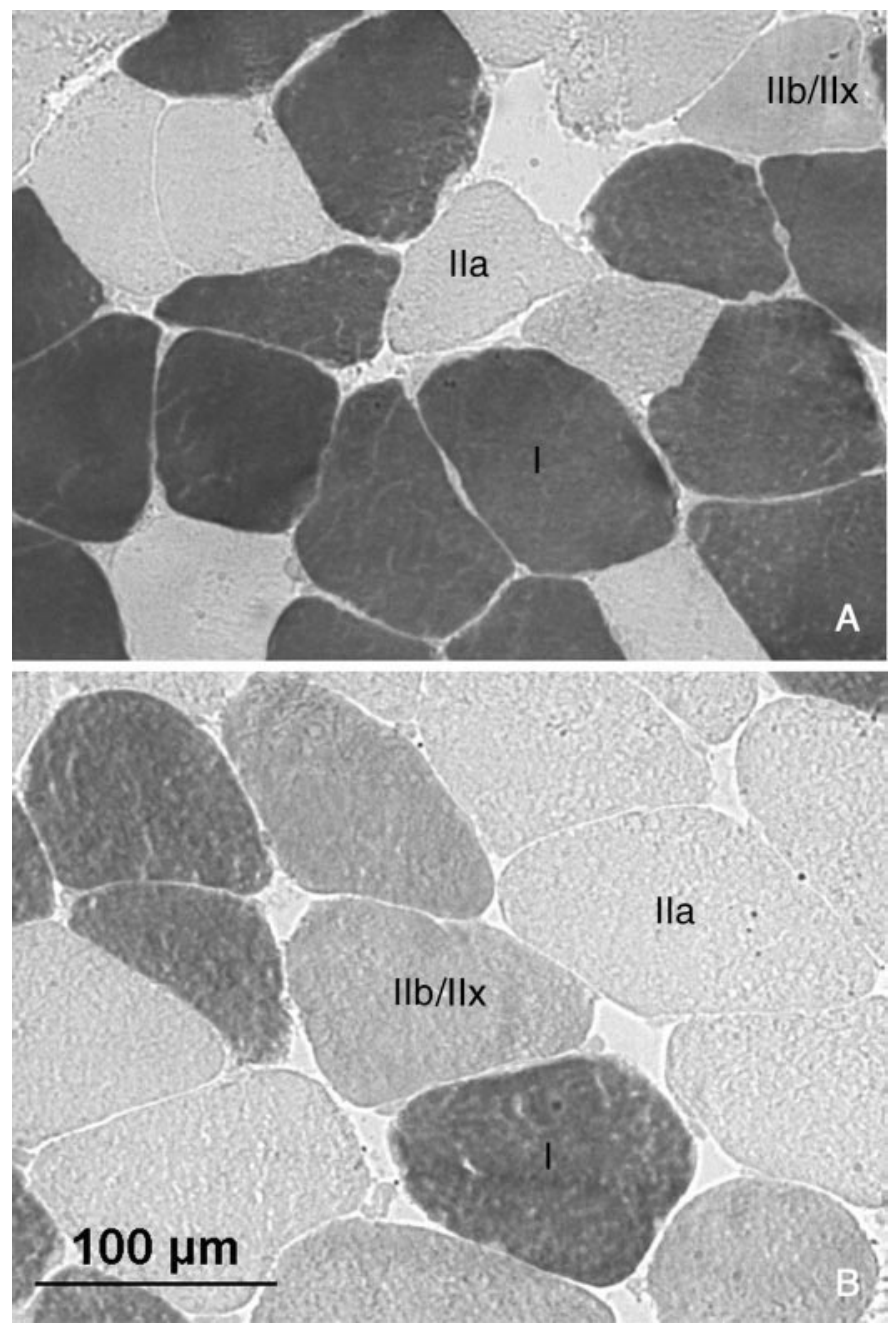

Fig. 1. Muscle fiber type analyses performed on muscle tissue collected from elderly $(A)$ and young $(B)$ males by ATPase staining of muscle cross sections; type I fibers are black, and type II fibers are white (IIa) or show intermediate staining (IIb/IIx). Type II fibers are significantly smaller in the elderly vs. the young. 
CD56 (mouse anti-CD56; BD Biosciences, San Jose, CA), which has been extensively used for SC determination in human muscle tissue $(10,15,22,23)$. Because of superior staining efficiency when using pax7, this marker was used for the quantification of SC in the present study. After fixation for $5 \mathrm{~min}$ with acetone, slides were air-dried and incubated for $60 \mathrm{~min}$ at room temperature with primary antibodies directed against laminin (dilution 1:50) and pax7 (dilution 1:20), diluted in $0.05 \%$ Tween-PBS. Slides were then washed for $3 \times 5 \mathrm{~min}$ in PBS before incubation for $60 \mathrm{~min}$ at room temperature with the appropriate secondary antibodies, purchased from Molecular Probes. Goat anti-rabbit IgG-AlexaFluor555 (dilution 1:200) and goat antimouse $\mathrm{IgG}_{1}$-AlexaFluor488 (dilution 1:500) were diluted together with DAPI $(0.238 \mu \mathrm{M})$ in $0.05 \%$ Tween-PBS to, respectively, stain laminin in red, pax7 in green, and myonuclei in blue (Fig. 2). After incubation, slides were again washed for $3 \times 5 \mathrm{~min}$ in PBS and then covered with cover glasses using Mowiol (Calbiochem, Amsterdam, The Netherlands).

Although pax7 is essential for the specification of SC, it has been reported that pax7 expression declines when SC ontogeny proceeds into terminal differentiation $(43,50)$. As such, the use of pax 7 staining as a marker for SC content could theoretically lead to an underestimation of total SC count. Therefore, we validated the use of pax7 by simultaneously staining cross sections of three young and three elderly subjects with pax7, CD56, and DAPI. In agreement with earlier findings (37), $>96 \%$ of CD56-positive SC were also pax7 positive, with no differences between age groups. In the present study, the term "satellite cells" (SC) refers to the number of SC that stained positive for pax7.

Data analyses. All images were digitally captured, using both light microscopy (ATPase) and fluorescence microscopy (laminin, pax7, and DAPI) with a Nikon E800 combined light/fluorescence microscope (Nikon Instruments Europe, Badhoevedorp, The Netherlands) coupled to a Basler A113 C progressive scan color CCD camera with a Bayer color filter. Epifluorescence signal was recorded using a Texas Red excitation filter $(540-580 \mathrm{~nm})$ for laminin, an FITC excitation filter (465-495 nm) for pax7, and a DAPI UV excitation filter (340-380 nm) for the nuclei. Image processing and quantitative analyses were done using Lucia 4.81 software package (Nikon). All image recordings and analyses were performed by an investigator blinded to the subject coding.

From the ATPase-stained slides, images were captured at $\times 120$ magnification. Laminin was used to determine cell borders, and for all fibers within each image, type I (black) and type II (white and intermediate) fibers were identified (Fig. 1). Within each image, the number of fibers, the mean fiber cross-sectional area (CSA), the number of myonuclei per fiber, and the mean fiber area per nucleus (fiber CSA/no. of myonuclei) were measured for the type I and type II fibers separately. As a measure of fiber circularity, form factors were calculated using the formula $(4 \pi \cdot \mathrm{CSA}) /(\text { perimeter })^{2}$. Fiber circularity was not different between the muscle cross sections from the elderly vs. the young for any fiber type.

From the pax7-stained slides, images were captured at $\times 240$ magnification to allow clear determination of SC localization. Laminin was used to visualize the cell borders. Fiber typing was determined by matching the serial ATPase-stained cross sections. SC were determined in each fiber between the basal lamina and the plasmamembrane and stained positive for both DNA (DAPI) and pax7 (see Fig. 2 for example). The data were used to calculate the number of SC per muscle fiber, the proportion of SC [no. of SC/(no. of SC + no. of
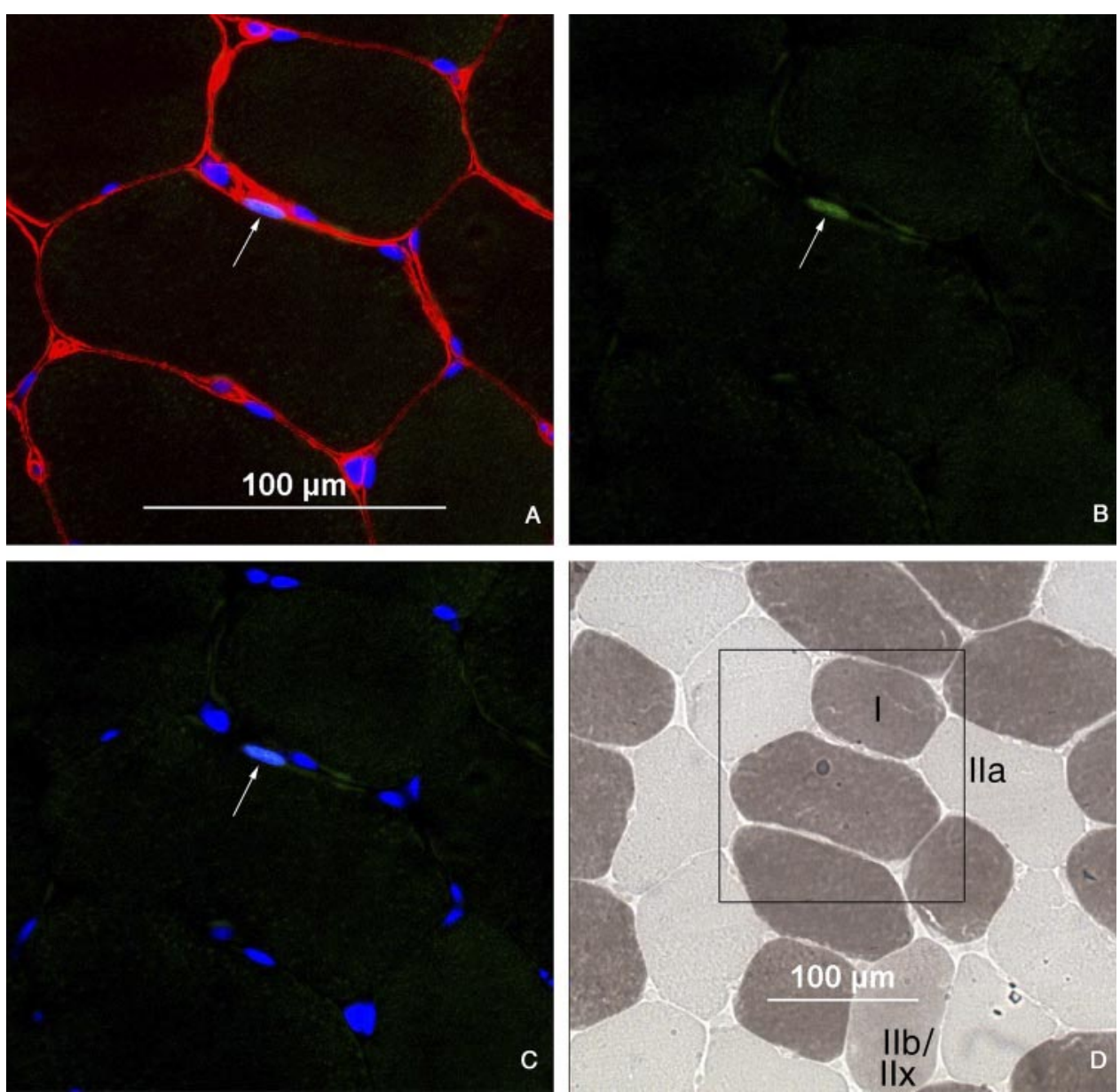

Fig. 2. Muscle fiber type analyses for satellite cell (SC) content. A: laminin + DAPI + pax7 staining. $B$ : only pax7 staining. $C$ : DAPI + pax7 staining. Arrows indicate the SC. $D$ : ATPase staining from serial muscle cross sections of images $A-C$; the marked area represents the same area as shown in $A-C$. 
myonuclei)], and the number of SC per fiber area (in $\mathrm{mm}^{2}$ ) for the type I and type II muscle fibers separately.

Because there were no differences in muscle fiber type composition and CSA of the type I and II fibers between muscle samples taken from the left vs. the right leg, muscle fiber data were pooled from both biopsies in each subject, resulting in a mean number of $401 \pm 32$ and $507 \pm 69$ individual muscle fibers being analyzed in the young and elderly subjects, respectively. For SC count, $287 \pm 26$ and $291 \pm 29$ fibers were analyzed in the muscle samples collected in the young and elderly subjects, respectively.

Statistics. All values are expressed as means \pm SE. Muscle characteristics in muscle biopsies collected from the left and right legs were analyzed using paired $t$-tests. General differences between elderly and young subjects were evaluated by independent $t$-tests. In addition, fiber type-specific variables were analyzed using mixedmodel analyses with "age group" (young and elderly) as the betweensubjects factor and "fiber type" (type I and II) as the within-subjects factor. In the case of significant interaction, between-group differences were analyzed for the different fiber types separately, and within-group differences were analyzed for the young and elderly separately. A $P$ level of 0.05 was used to determine statistical significance. All analyses were performed using SPSS version 11.5 (Chicago, IL).

\section{RESULTS}

Subjects. Subject characteristics are provided in Table 1. Basal blood glucose and insulin levels and whole body insulin sensitivity as assessed by the homeostasis model assessment of insulin resistance (HOMA-IR) index (31) did not differ between groups. Blood $\mathrm{Hb} \mathrm{A}_{1 \mathrm{c}}$ concentrations were within a normal range for both groups but were significantly greater in the elderly. Muscle strength as assessed by 1-RM for both leg press and leg extension was significantly lower in the elderly (151 \pm 7 and $78 \pm 4 \mathrm{~kg}$, respectively) vs. the young (204 \pm 7 and $108 \pm 4 \mathrm{~kg}$, respectively; $P<0.001)$. The latter was accompanied by a lower leg volume in the elderly compared with the young. In accordance, leg volume was significantly correlated with muscle strength $(r=0.53 ; P<0.05)$.

Fiber characteristics. Fiber type composition was significantly different between groups (Table 2). Type II muscle fiber content was significantly lower in the elderly $(47 \pm 3 \%)$ vs. the young $(57 \pm 3 \% ; P<0.05)$. In addition, the percentage of total muscle area occupied by type II fibers was also significantly smaller in the elderly $(42 \pm 4 \%)$ vs. the young $(59 \pm$ $3 \% ; P<0.01)$. Type II, but not type I, muscle fiber CSA differed significantly between groups, with mean type II muscle fiber CSA being smaller in the elderly vs. the young $\left(4,451 \pm 396\right.$ vs. $6,126 \pm 393{\mu \mathrm{m}^{2}}^{2}$, respectively; $\left.P<0.05\right)$ (Table 2, Fig. 1). There was a significant interaction between age group and fiber type CSA $(P<0.05)$. In the young, fiber

Table 2. Muscle fiber characteristics

\begin{tabular}{|c|c|c|c|c|c|c|}
\hline & \multicolumn{3}{|c|}{ Young } & \multicolumn{3}{|c|}{ Elderly } \\
\hline & $\mathrm{CSA}, \mu \mathrm{m}^{2}$ & $\%$ Fiber & $\% \mathrm{CSA}$ & $\mathrm{CSA}, \mu \mathrm{m}^{2}$ & \%Fiber & $\% \mathrm{CSA}$ \\
\hline Type I & $5,589 \pm 281$ & $43 \pm 3$ & $41 \pm 3$ & $5,471 \pm 227$ & $53 \pm 3^{*}$ & $58 \pm 4 *$ \\
\hline Type II & $6,126 \pm 393$ & $57 \pm 3$ & $59 \pm 3$ & $4,451 \pm 396^{* \dagger} \dagger$ & $47 \pm 3 *$ & $42 \pm 4 *$ \\
\hline
\end{tabular}

Values are means \pm SE. CSA, fiber cross-sectional area; \%CSA, \%muscle area occupied per fiber type. For CSA, a significant interaction between group and fiber type was found. *Significantly different compared with the young $(P<0.05)$. $\dagger$ CSA significantly different compared with the type I muscle fibers (within groups, $P<0.05$ ).
CSA did not differ between fiber types. In contrast, in the elderly muscle fiber CSA was significantly smaller in the type II vs. the type I fibers $(P<0.05$; Table 2$)$.

Myonuclei. In both the young and elderly, the number of myonuclei per fiber was significantly higher in the type I muscle fibers compared with the type II muscle fibers (Table 3 ). In accordance, the fiber area per myonucleus was smaller for the type I vs. the type II muscle fibers. The number of myonuclei per muscle fiber differed significantly between groups for both the type I and II muscle fibers (Table 3). More myonuclei were present per type I and II muscle fibers in the elderly compared with the young (type I, $3.5 \pm 0.2$ vs. $3.0 \pm$ 0.2 , and type II, $2.6 \pm 0.1$ vs. $2.3 \pm 0.1$, respectively; $P<$ $0.01)$. For the fiber area per myonucleus, there was significant interaction between age group and fiber type. Separate analysis showed significant differences between groups, with the elderly showing a significantly smaller fiber area per myonucleus in both the type I and II muscle fibers when compared with the young, the latter difference being more pronounced in the type II muscle fibers (Table 3; $P<0.05$ ).

$S C$. In type I muscle fibers, no differences were observed in $\mathrm{SC}$ content, neither as the number of SC per fiber nor as the number of SC per millimeter squared $\left(\mathrm{mm}^{2}\right)$, between the young and the elderly (Table 3 ). In addition, SC proportion in type I fibers did not differ between the young and the elderly. In contrast, in the type II muscle fibers, SC content was significantly lower in the elderly vs. the young. The number of SC per type II muscle fiber was significantly reduced in the elderly when compared with the young $(0.044 \pm 0.003$ vs. $0.080 \pm 0.007$, respectively, $P<0.01$; Fig. 3 ). The latter was also evident when correcting for CSA, as the number of SC per $\mathrm{mm}^{2}$ of type II muscle fiber was also significantly reduced in the elderly compared with the young $(9.7 \pm 1.0$ vs. $12.6 \pm 0.9$, respectively; $P<0.05)$. In accordance, $\mathrm{SC}$ proportion was significantly different between groups, with SC representing $1.5 \pm 0.2 \%$ of nuclei in the elderly type II muscle fibers compared with $2.9 \pm 0.4 \%$ in type II muscle fibers of the young $(P<0.01)$. For all $\mathrm{SC}$ variables, there was a significant interaction between age group and fiber type. In the young, no significant differences were observed for any of the SC characteristics between the type I and II muscle fibers. In the elderly, the number of SC per muscle fiber, the number of SC per $\mathrm{mm}^{2}$ of muscle fiber, and the proportion of $\mathrm{SC}$ were substantially lower in the type II vs. the type I muscle fibers (Table 3 and Fig. 3).

\section{DISCUSSION}

In the present study, we confirm that both the proportion and CSA of the type II skeletal muscle fibers are substantially reduced in skeletal muscle tissue in the elderly. As far as we know, this is the first report that shows that type II muscle fiber atrophy in the elderly is associated with a specific reduction in the number of SC in these fibers. The latter is evident when expressed as number of SC per muscle fiber, as proportion of $\mathrm{SC}$ relative to the total number of nuclei, or as number of SC per muscle fiber area. This muscle fiber type-specific decline in SC content might represent an important factor in the etiology of sarcopenia.

Numerous studies have demonstrated that the age-related loss of skeletal muscle mass is characterized by a reduction in 
Table 3. Myonuclei and satellite cell characteristics

\begin{tabular}{llcc}
\hline \hline & $\begin{array}{c}\text { Type } \\
\text { (I vs. II) }\end{array}$ & Young & Elderly \\
\hline Nuclei/fiber & Type I & $3.0 \pm 0.2$ & $3.5 \pm 0.2^{*}$ \\
& Type II & $2.3 \pm 0.1 \dagger$ & $2.6 \pm 0.1^{* \dagger}$ \\
Fiber area/nucleus, $\mu \mathrm{m}^{2}$ & Type I & $1,849 \pm 71$ & $1,562 \pm 56^{*}$ \\
& Type II & $2,549 \pm 129 \dagger$ & $1,760 \pm 104^{* \dagger}$ \\
SC/fiber & Type I & $0.071 \pm 0.006$ & $0.082 \pm 0.005$ \\
& Type II & $0.080 \pm 0.007$ & $0.044 \pm 0.003^{* \dagger}$ \\
$\% \mathrm{SC}$ & Type I & $2.4 \pm 0.1$ & $2.4 \pm 0.2$ \\
& Type II & $2.9 \pm 0.4$ & $1.5 \pm 0.2 * \dagger$ \\
$\mathrm{SC} / \mathrm{mm}^{2}$ & Type I & $12.7 \pm 1.1$ & $13.8 \pm 1.0$ \\
& Type II & $12.6 \pm 0.9$ & $9.7 \pm 1.0^{* \dagger}$ \\
\hline
\end{tabular}

Values are means \pm SE. SC, satellite cells; \%SC, SC proportion [no. of $\mathrm{SC} /($ no. of $\mathrm{SC}+$ no. of myonuclei)]. *Significantly different compared with the young $(P<0.05)$. $\dagger$ Significantly different compared with the type I muscle fibers (within groups, $P<0.05$ ).

the total number of muscle fibers and specific atrophy of the type II muscle fibers $(18,29,30,45)$. The decline in maximal strength with age has been attributed to this gradual loss of skeletal muscle tissue, but other intrinsic changes, e.g., fiber type shifts and reduced concentrations of contractile material, could also contribute to this phenomenon $(6,12)$. Our data seem to confirm earlier reports $(26,27,48)$ showing a reduced leg volume and muscle strength in the elderly vs. the young (Table 1). Furthermore, at the muscle level, we observed a significantly higher percentage of type I muscle fibers and the specific atrophy of the type II muscle fibers in the elderly (Table 2). These findings are consistent with previous reports $(15,28,45)$ and are likely responsible for the reduced muscle strength in the elderly (Table 1).

Even though the changes in muscle fiber type composition and morphology with aging have been described rather consistently in the literature, there is still considerable debate on the underlying mechanisms responsible for these changes. It has been suggested that $\mathrm{SC}$ content in muscle plays an important role in the age-related changes in skeletal muscle structure and function (44). However, although this topic has received much attention over the past 10 years $(10,15,19,20,22,38$, $40,41,47)$, the exact changes in the SC pool that occur with aging still remain unresolved. Two recent studies have reported a decline in SC content with aging in the tibialis anterior (22) and in the biceps and masseter muscle (38) in humans. In contrast, other studies failed to observe such differences in either SC proportion or the number of SC in muscle fibers taken from the vastus lateralis muscle in young vs. elderly subjects $(15,20,40)$. The apparent discrepancy between these findings might be attributed to differences in study design, e.g., selection of subject age, the number of fibers analyzed, and the specific muscle group studied.

So far, studies investigating age-related differences in SC content in human skeletal muscle have been limited to mixed muscle fiber analyses. In contrast to the fiber type-specific differences in SC content that have been consistently shown in rodent muscle (17, 42, 44), Kadi et al. (23) recently reported no differences in SC content between type I and II muscle fibers in young adults. However, because sarcopenia is associated with the specific atrophy of type II muscle fibers, we hypothesized that fiber type differences in SC content might exist at an older age. Therefore, in the present study, we determined type I and II muscle fiber type-specific SC content in both young and elderly men. In accordance with Kadi et al. (23), we observed $\sim 0.075$ SC per muscle fiber, with no differences between the type I and II muscle fibers in the young subjects (Table 3). Extending their findings and consistent with the specific atrophy of type II muscle fibers with aging, we observed a $44 \pm 6 \%$ lower SC content in the type II vs. type I muscle fibers in the elderly. Furthermore, SC content in the type II muscle fibers in the elderly was significantly lower when compared with type II muscle fiber SC content in the young (Table 3, Fig. 3). Notably, even when correcting for fiber CSA, type II muscle fiber SC content was still significantly lower in the elderly vs. the young (Table 3 ). These data support the idea that SC content is strongly associated with myofiber maintenance and imply that the age-related reduction in type II muscle fiber SC content might represent an important factor in the specific loss and atrophy of type II muscle fibers with aging.

As stated in METHODS, we used pax7 staining to assess muscle fiber type-specific SC content in skeletal muscle cross sections. It should be noted that a slight proportion of SC may be $\operatorname{pax} 7$ negative in vivo, i.e., those SC that are progressing into terminal differentiation $(43,50)$. Therefore, we crossvalidated our data by double staining with anti-CD56 in a subset of muscle samples. The vast majority of SC were both CD56 and pax7 positive, with no differences between the young and elderly (94.9 vs. $96.5 \%$, respectively). As such, the latter could not be responsible for the substantial differences in skeletal muscle fiber SC content between groups.

Findings from several rodent $(7,39,44)$ as well as human studies $(10,25,46)$ suggest that the abundance of SC within skeletal muscle fibers represents an important factor determining the capacity for myofiber maintenance. On the other hand, type II myofiber atrophy and a reduction in SC content might also be caused by one and the same phenomenon, e.g., decreased neuronal input (13). In addition, Bonavaud et al. (4) recently reported that myotubes formed by the fusion of human $\mathrm{SC}$ from either fast or slow muscle fibers in vitro express both fast and slow MHC isoforms. This finding would argue against a direct causal link between type II fiber SC loss and atrophy, as the loss of SC could theoretically be compensated for by



Fig. 3. SC content in type I and II muscle fibers in the young vs. the elderly. *Significantly different compared with the young $(P<0.01)$. \#Significantly different compared with the type I muscle fibers $(P<0.01)$. 
incorporating SC progeny from type I fibers. However, the latter has yet to be established, and one could argue that, in an in vivo situation, where SC progeny generally fuse with existing fibers, expression of fast MHC isoforms by SC originating from slow fibers might not occur.

Our data support the idea that SC abundance is an important factor regulating myofiber size. In addition, the reduced SC content in type II fibers in the elderly might attenuate their response to anabolic stimuli, stressing the need for potent interventions for reversing the loss of skeletal muscle mass and function with aging. Nevertheless, a direct causal link between $\mathrm{SC}$ loss and myofiber atrophy remains to be established. Furthermore, qualitative changes (e.g., blunted SC activation) likely play another important role in the impaired regenerative capacity of skeletal muscle tissue with aging. As such, endocrine changes as well as changes in the local SC environment with aging might also contribute to the loss of $\mathrm{SC}$ due to the prevention of SC self-renewal $(11,14,44)$. At this moment, we can only speculate on the potential causes and clinical relevance of qualitative and quantitative changes in skeletal muscle fiber SC content with aging, and more research is warranted.

In conclusion, this study is the first to show that SC content is specifically reduced in the type II muscle fibers in elderly men. The latter is shown to be evident when SC content is expressed as number of SC per fiber as well as number of SC per fiber area. The fiber type-specific reduction in SC content might represent an important regulatory factor in the loss of skeletal muscle mass, structure, and function with aging.

\section{REFERENCES}

1. Alberti KG, Zimmet PZ. Definition, diagnosis and classification of diabetes mellitus and its complications. Part 1: diagnosis and classification of diabetes mellitus provisional report of a WHO consultation. Diabet Med 15: 539-553, 1998.

2. Allen DL, Roy RR, Edgerton VR. Myonuclear domains in muscle adaptation and disease. Muscle Nerve 22: 1350-1360, 1999.

3. Bergstrom J. Percutaneous needle biopsy of skeletal muscle in physiological and clinical research. Scand J Clin Lab Invest 35: 609-616, 1975.

4. Bonavaud S, Agbulut O, Nizard R, D'Honneur G, Mouly V, ButlerBrowne G. A discrepancy resolved: human satellite cells are not preprogrammed to fast and slow lineages. Neuromuscul Disord 11: 747-752, 2001.

5. Borghouts LB, Schaart G, Hesselink MK, Keizer HA. GLUT-4 expression is not consistently higher in type-1 than in type-2 fibres of rat and human vastus lateralis muscles; an immunohistochemical study. Pflügers Arch 441: 351-358, 2000.

6. Bottinelli R, Reggiani C. Human skeletal muscle fibres: molecular and functional diversity. Prog Biophys Mol Biol 73: 195-262, 2000.

7. Brack AS, Bildsoe H, Hughes SM. Evidence that satellite cell decrement contributes to preferential decline in nuclear number from large fibres during murine age-related muscle atrophy. J Cell Sci 118: 4813-4821, 2005 .

8. Brooke MH, Kaiser KK. Muscle fiber types: how many and what kind? Arch Neurol 23: 369-379, 1970.

9. Brooke MH, Kaiser KK. Three "myosin adenosine triphosphatase" systems: the nature of their $\mathrm{pH}$ lability and sulfhydryl dependence. J Histochem Cytochem 18: 670-672, 1970.

10. Charifi N, Kadi F, Feasson L, Denis C. Effects of endurance training on satellite cell frequency in skeletal muscle of old men. Muscle Nerve 28: 87-92, 2003

11. Conboy IM, Conboy MJ, Wagers AJ, Girma ER, Weissman IL, Rando TA. Rejuvenation of aged progenitor cells by exposure to a young systemic environment. Nature 433: 760-764, 2005.

12. D'Antona G, Pellegrino MA, Adami R, Rossi R, Carlizzi CN, Canepari M, Saltin B, Bottinelli R. The effect of ageing and immobilization on structure and function of human skeletal muscle fibres. J Physiol 552: 499-511, 2003.
13. Delbono O. Neural control of aging skeletal muscle. Aging Cell 2: 21-29, 2003.

14. Dhawan J, Rando TA. Stem cells in postnatal myogenesis: molecular mechanisms of satellite cell quiescence, activation and replenishment. Trends Cell Biol 15: 666-673, 2005.

15. Dreyer HC, Blanco CE, Sattler FR, Schroeder ET, Wiswell RA. Satellite cell numbers in young and older men 24 hours after eccentric exercise. Muscle Nerve 33: 242-253, 2006.

16. Fiatarone MA, Marks EC, Ryan ND, Meredith CN, Lipsitz LA, Evans WJ. High-intensity strength training in nonagenarians. Effects on skeletal muscle. JAMA 263: 3029-3034, 1990.

17. Gibson MC, Schultz E. Age-related differences in absolute numbers of skeletal muscle satellite cells. Muscle Nerve 6: 574-580, 1983.

18. Grimby G. Muscle performance and structure in the elderly as studied cross-sectionally and longitudinally. J Gerontol A Biol Sci Med Sci 50: 17-22, 1995.

19. Hawke TJ, Garry DJ. Myogenic satellite cells: physiology to molecular biology. J Appl Physiol 91: 534-551, 2001.

20. Hikida RS, Walsh S, Barylski N, Campos G, Hagerman FC, Staron RS. Is hypertrophy limited in elderly muscle fibers? A comparison of elderly and young strength-trained men. Basic Appl Myol 8: 419-427, 1998.

21. Jones PR, Pearson J. Anthropometric determination of leg fat and muscle plus bone volumes in young male and female adults. $J$ Physiol 204: 63P-66P, 1969.

22. Kadi F, Charifi N, Denis C, Lexell J. Satellite cells and myonuclei in young and elderly women and men. Muscle Nerve 29: 120-127, 2004.

23. Kadi F, Charifi N, Henriksson J. The number of satellite cells in slow and fast fibres from human vastus lateralis muscle. Histochem Cell Biol: $1-5,2005$.

24. Kadi F, Schjerling P, Andersen LL, Charifi N, Madsen JL, Christensen LR, Andersen JL. The effects of heavy resistance training and detraining on satellite cells in human skeletal muscles. J Physiol 558: 1005-1012, 2004.

25. Kadi F, Thornell LE. Concomitant increases in myonuclear and satellite cell content in female trapezius muscle following strength training. Histochem Cell Biol 113: 99-103, 2000.

26. Kim JS, Cross JM, Bamman MM. Impact of resistance loading on myostatin expression and cell cycle regulation in young and older men and women. Am J Physiol Endocrinol Metab 288: E1110-E1119, 2005.

27. Klitgaard H, Mantoni M, Schiaffino S, Ausoni S, Gorza L, LaurentWinter C, Schnohr P, Saltin B. Function, morphology and protein expression of ageing skeletal muscle: a cross-sectional study of elderly men with different training backgrounds. Acta Physiol Scand 140: 41-54, 1990.

28. Larsson L, Sjodin B, Karlsson J. Histochemical and biochemical changes in human skeletal muscle with age in sedentary males, age 22-65 years. Acta Physiol Scand 103: 31-39, 1978.

29. Lexell J. Human aging, muscle mass, and fiber type composition. $J$ Gerontol A Biol Sci Med Sci 50: 11-16, 1995.

30. Lexell J, Taylor CC, Sjostrom M. What is the cause of the ageing atrophy? Total number, size and proportion of different fiber types studied in whole vastus lateralis muscle from 15- to 83-year-old men. J Neurol Sci 84: 275-294, 1988.

31. Matthews DR, Hosker JP, Rudenski AS, Naylor BA, Treacher DF, Turner RC. Homeostasis model assessment: insulin resistance and betacell function from fasting plasma glucose and insulin concentrations in man. Diabetologia 28: 412-419, 1985.

32. Mauro A. Satellite cell of skeletal muscle fibers. J Biophys Biochem Cytol 9: 493-495, 1961

33. Mayhew JL, Prinster JL, Ware JS, Zimmer DL, Arabas JR, Bemben MG. Muscular endurance repetitions to predict bench press strength in men of different training levels. J Sports Med Phys Fitness 35: 108-113, 1995.

34. Moss FP, Leblond CP. Nature of dividing nuclei in skeletal muscle of growing rats. J Cell Biol 44: 459-462, 1970.

35. Moss FP, Leblond CP. Satellite cells as the source of nuclei in muscles of growing rats. Anat Rec 170: 421-435, 1971.

36. Rantanen T, Avlund K, Suominen H, Schroll M, Frandin K, Pertti E. Muscle strength as a predictor of onset of ADL dependence in people aged 75 years. Aging Clin Exp Res 14: 10-15, 2002.

37. Reimann J, Brimah K, Schroder R, Wernig A, Beauchamp JR, Partridge TA. Pax7 distribution in human skeletal muscle biopsies and myogenic tissue cultures. Cell Tissue Res 315: 233-242, 2004. 
38. Renault V, Thornell LE, Eriksson PO, Butler-Browne G, Mouly V. Regenerative potential of human skeletal muscle during aging. Aging Cell 1: 132-139, 2002.

39. Rosenblatt JD, Yong D, Parry DJ. Satellite cell activity is required for hypertrophy of overloaded adult rat muscle. Muscle Nerve 17: 608-613, 1994.

40. Roth SM, Martel GF, Ivey FM, Lemmer JT, Metter EJ, Hurley BF, Rogers MA. Skeletal muscle satellite cell populations in healthy young and older men and women. Anat Rec 260: 351-358, 2000.

41. Roth SM, Martel GF, Ivey FM, Lemmer JT, Tracy BL, Metter EJ, Hurley BF, Rogers MA. Skeletal muscle satellite cell characteristics in young and older men and women after heavy resistance strength training. J Gerontol A Biol Sci Med Sci 56: B240-B247, 2001.

42. Schmalbruch $\mathbf{H}$, Hellhammer $\mathbf{U}$. The number of nuclei in adult rat muscles with special reference to satellite cells. Anat Rec 189: 169-175, 1977.

43. Seale P, Sabourin LA, Girgis-Gabardo A, Mansouri A, Gruss P, Rudnicki MA. Pax7 is required for the specification of myogenic satellite cells. Cell 102: 777-786, 2000.

44. Shefer G, Van de Mark DP, Richardson JB, Yablonka-Reuveni Z. Satellite-cell pool size does matter: defining the myogenic potency of aging skeletal muscle. Dev Biol 294: 50-66, 2006.
45. Singh MA, Ding W, Manfredi TJ, Solares GS, O’Neill EF, Clements KM, Ryan ND, Kehayias JJ, Fielding RA, Evans WJ. Insulin-like growth factor I in skeletal muscle after weight-lifting exercise in frail elders. Am J Physiol Endocrinol Metab 277: E135-E143, 1999.

46. Sinha-Hikim I, Roth SM, Lee MI, Bhasin S. Testosterone-induced muscle hypertrophy is associated with an increase in satellite cell number in healthy, young men. Am J Physiol Endocrinol Metab 285: E197-E205, 2003.

47. Thornell LE, Lindstrom M, Renault V, Mouly V, Butler-Browne GS. Satellite cells and training in the elderly. Scand J Med Sci Sports 13: 48-55, 2003.

48. Volpi E, Sheffield-Moore M, Rasmussen BB, Wolfe RR. Basal muscle amino acid kinetics and protein synthesis in healthy young and older men. JAMA 286: 1206-1212, 2001.

49. Wolfson L, Judge J, Whipple R, King M. Strength is a major factor in balance, gait, and the occurrence of falls. J Gerontol A Biol Sci Med Sci 50: 64-67, 1995.

50. Zammit PS, Golding JP, Nagata Y, Hudon V, Partridge TA, Beauchamp JR. Muscle satellite cells adopt divergent fates: a mechanism for self-renewal? J Cell Biol 166: 347-357, 2004.



